Supporting Information

\title{
RAFT Emulsion Polymerization: MacroRAFT Agent Self- Assembly Investigated Using a Solvachromatic Dye
}

Steven W. Thompson, Thiago R. Guimarães, and Per B. Zetterlund*

Centre for Advanced Macromolecular Design (CAMD), School of Chemical Engineering, The University of New South Wales, Sydney, NSW 2052, Australia. 


\section{Synthesis of 4-cyano-4-(((butylthio)carbonothioyl)thio)pentanoic acid (RAFT-2).}

A $50 \% \mathrm{NaOH}$ solution ( $4.20 \mathrm{~g}$, containing $2.10 \mathrm{~g}, 52 \mathrm{mmol}$ of $\mathrm{NaOH}$ ) was added to a stirred mixture of butanethiol $(4.7 \mathrm{~g}, 52 \mathrm{mmol})$ and water $(8 \mathrm{~mL})$. Acetone $(2.6 \mathrm{~mL})$ was then added, and the resulting clear colorless solution was stirred for $0.5 \mathrm{~h}$. The solution was cooled to nearroom temperature and treated with carbon disulfide $(4.5 \mathrm{~g}, 3.7 \mathrm{~mL}, 58.5 \mathrm{mmol})$ to give a clear orange solution. The reaction was carried out for 1 hour at room temperature under $\mathrm{N}_{2}$. Potassium ferricyanete water solution $(20.6 \mathrm{~g}$ in $70 \mathrm{~mL})$ was then added dropwise forming greenish/brown aqueous solution with orange oil droplets in suspension. The reaction proceeds for 1 hour at room temperature. The product was extract with diethyl ether, $40 \mathrm{~mL}$, and the remaining aqueous phase washed twice with $20 \mathrm{~mL}$ of diethyl ether. The organic phases were combined and dried with $\mathrm{MgSO}_{4}$. After solvent extraction under vacuum, the product bis(propylsulfanylthiocarbonyl) disulfide, an orange oil, was obtained.

Bis(propylsulfanylthiocarbonyl) dissulfite $\quad(7.09 \mathrm{~g}, 21.4 \mathrm{mmol})$ and 4'4'-azobis(4cyanopentanoic) acid $(7.4 \mathrm{~g}, 25.9 \mathrm{mmol})$ were solubilized in $50 \mathrm{~mL}$ of ethyl acetate and the resulting dispersion (solids in suspension) was degassed for 30min under nitrogen flux. The reaction system was immersed in an oil bath at $94^{\circ} \mathrm{C}$ and the reaction conducted under reflux overnight. A clear orange solution was obtained resulting in an orange oil after solvent extraction. The product was purified by chromatography column using a mixture of diethyl ether and heptane $(\mathrm{vol} / \mathrm{vol}=1 / 2)$ for elution of impurities and, then, diethyl ether for the product elution. The solvent was extracted under vacuum and an orange oil was obtained. ${ }^{1} \mathrm{H}$ NMR $\left(\mathrm{CDCl}_{3}\right): \delta(\mathrm{ppm}) 0.97\left(\mathrm{t}, 3 \mathrm{H}, \mathrm{CH}_{3}-\mathrm{CH}_{2}-\right) ; 1.46\left(\mathrm{~m}, 2 \mathrm{H}, \mathrm{CH}_{3}-\mathrm{CH}_{2}-\mathrm{CH}_{2}-\right) ; 1.72\left(\mathrm{~m}, 2 \mathrm{H},-\mathrm{CH}_{2^{-}}\right.$ $\left.\mathrm{CH}_{2}-\mathrm{CH}_{2}-\right), 1.92\left(\mathrm{~s}, 3 \mathrm{H}, \quad-\mathrm{CH}_{2}-\mathrm{C}(\mathrm{CN})\left(\mathrm{CH}_{3}\right)-\mathrm{S}-\right) ; 2.37 \sim 2.74 \quad\left(\mathrm{~m}, 4 \mathrm{H}, \quad-\mathrm{OOC}-\mathrm{CH}_{2}-\mathrm{CH}_{2}-\right.$ $\left.\mathrm{C}(\mathrm{CN})\left(\mathrm{CH}_{3}\right)-\right) ; 3.37$ (t, 2H, $\left.-\mathrm{CH}_{2}-\mathbf{C H}_{2}-\mathrm{S}-\right)$. 
Table SI1 - Experimental conditions and results for the synthesis of hydrophilic macroRAFT agents via RAFT solution polymerization in water or 1,4-Dioxane.

\begin{tabular}{|c|c|c|c|c|c|c|c|c|}
\hline MacroRAFT & $\begin{array}{l}\text { RAFT } \\
\text { agent }^{\text {a }}\end{array}$ & Solvent & [Mon] $\left(\mathrm{mmol} \mathrm{L} \mathbf{L}^{-1}\right)$ & $\begin{array}{l}\text { [Mon]/ } \\
\text { [Raft] }\end{array}$ & $\begin{array}{l}\text { [RAFT]/ } \\
\text { [ACPA] }\end{array}$ & $\mathbf{X} \% / \mathrm{t}(\mathrm{h})$ & $\mathbf{M}_{\mathrm{n}, \mathrm{th}}$ & $\mathbf{M}_{\mathbf{n}, \mathbf{e x p}} / \mathbf{Ð}$ \\
\hline $\mathbf{P A A}_{42}$-Ac & RAFT-1 & Water & 1021 & 41.8 & 39.5 & $100 / 24$ & 3320 & $2860 / 1.10$ \\
\hline $\mathbf{P A A}_{42}-\mathrm{C} 4$ & RAFT-2 & Water & 1541 & 43.2 & 39.9 & $97 / 22$ & 3310 & $3440 / 1.12$ \\
\hline $\mathrm{PAA}_{46}-\mathrm{C} 12$ & RAFT-3 & $\begin{array}{c}1,4- \\
\text { Dioxane }\end{array}$ & 3000 & 48.1 & 19.9 & $96 / 6$ & 3690 & $3370 / 1.15$ \\
\hline $\mathbf{P M A A}_{43}-\mathbf{A c}$ & RAFT-1 & Water & 1001 & 43.8 & 38.5 & $99 / 22$ & 4050 & $3830 / 1.13$ \\
\hline $\mathrm{PMAA}_{20}-\mathrm{C} 4$ & RAFT-2 & Water & 1325 & 20.1 & 38.7 & $99 / 23$ & 2010 & $2130 / 1.29$ \\
\hline PMAA $_{41}-\mathrm{C} 4$ & RAFT-2 & Water & 986 & 43.5 & 39.8 & $94 / 16$ & 3820 & $3810 / 1.18$ \\
\hline PMAA $_{60}-\mathrm{C} 4$ & RAFT-2 & Water & 1313 & 60.1 & 39.2 & $99 / 23$ & 5440 & $5200 / 1.15$ \\
\hline PMAA $_{119}-\mathrm{C} 4$ & RAFT-2 & Water & 1327 & 121.2 & 35.4 & $98 / 23$ & 10550 & $10170 / 1.12$ \\
\hline PMAA $_{42}-\mathrm{C} 12$ & RAFT-4 & $\begin{array}{c}1,4- \\
\text { Dioxane }\end{array}$ & 1360 & 45.7 & 19.7 & $93 / 20$ & 4070 & $5450 / 1.20$ \\
\hline PMAA42 $_{42}-\mathrm{C4}$ & RAFT-2 & Water & 988 & 43.3 & 40.2 & $98 / 24$ & 3980 & $3930 / 1.13$ \\
\hline
\end{tabular}

a RAFT-1 = 4-((((2-carboxyethyl)thio)carbonothioyl)thio)-4-cyanopentanoic acid; RAFT-2 - 4-cyano-4-(((butylthio)carbonothioyl)thio)pentanoic acid (CTPBA); RAFT 3 2-(dodecylthiocarbonothioylthio)propionic acid (DoPAT) and RAFT-4 4-cyano-4-(((dodecylthio)carbonothioyl)thio)pentanoic acid (CDTPA). Chemical structures presented in Scheme 1 (main text) 
(A) $\mathrm{PAA}_{42}-\mathrm{Ac}$

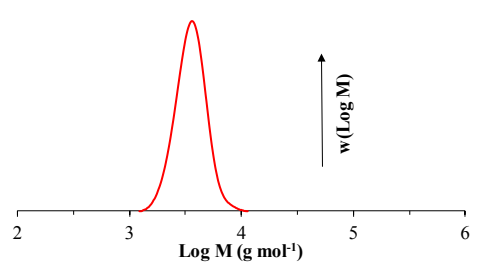

(D) $\mathrm{PMAA}_{43}-\mathrm{Ac}$

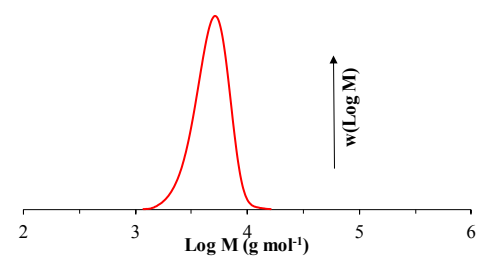

(G) PMAA $_{60}-\mathrm{C} 4$

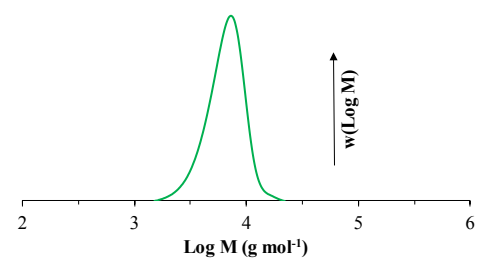

(B) $\mathrm{PAA}_{42}-\mathrm{C} 4$

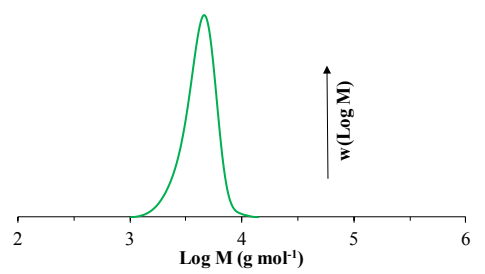

(E) $\mathrm{PMAA}_{20}-\mathrm{C} 4$

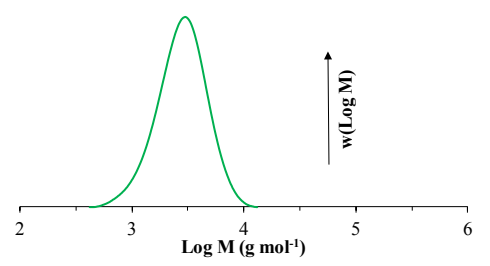

(H) PMAA $_{119}-\mathrm{C} 4$

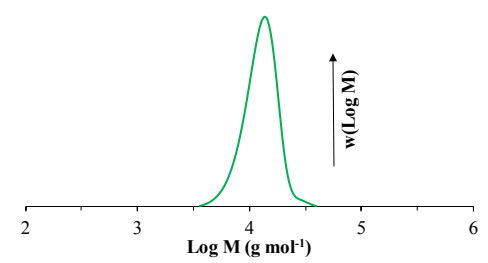

(C) $\mathrm{PAA}_{46}-\mathrm{C} 12$

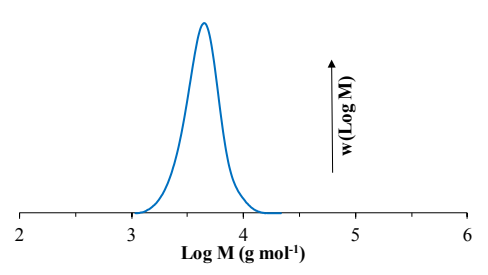

(F) $\mathrm{PMAA}_{41}-\mathrm{C} 4$

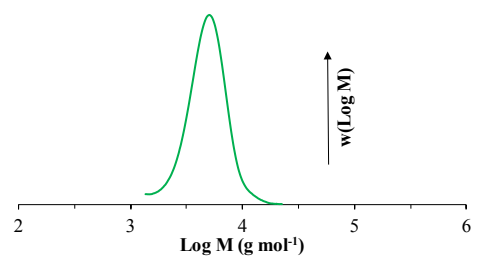

(I) $\mathrm{PMAA}_{42}-\mathrm{C} 12$

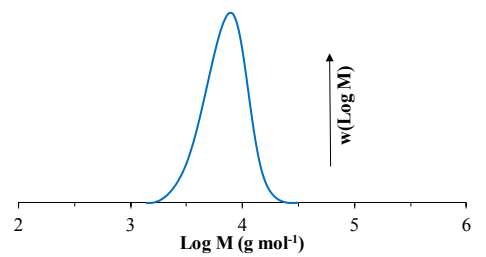

Figure SI1 - Molecular weight distributions of hydrophilic macroRAFT agents synthesized by RAFT solution polymerization based on recipe in Table SI1 
Table SI2 - Experimental conditions and results for the synthesis of amphiphilic macroRAFT via one-pot RAFT solution polymerization in 1,4-Dioxane at $80^{\circ} \mathrm{C}$

\begin{tabular}{|c|c|c|}
\hline MacroRAFT & $\begin{array}{c}\text { PMAA }_{62}-b-{ }^{-P M M A} \\
\text { C12 }\end{array}$ & $\mathrm{PAA}_{24}-b-\mathrm{PS}_{6}-\mathrm{C} 12$ \\
\hline RAFT agent & RAFT -4 & RAFT -3 \\
\hline \multicolumn{3}{|l|}{$1^{\text {st }}$ Stage } \\
\hline [Mon] & 2320 & 3200 \\
\hline$[\mathrm{Mon}] /[\mathrm{Raft}]$ & 41 & 25 \\
\hline [RAFT]/[ACPA] & 20 & 10.4 \\
\hline $\mathrm{X}_{\mathrm{MAA} \text { or AA }}$ & $75 / 5$ & $91 / 6$ \\
\hline $\mathrm{L} \%$ & 95.4 & 91 \\
\hline \multicolumn{3}{|l|}{$2^{\text {nd }}$ Stage } \\
\hline [Mon] & 2190 & 960 \\
\hline$[\mathrm{Mon}] /[\mathrm{Raft}]$ & 9.7 & 9.6 \\
\hline $\mathrm{X}_{\text {MAA or AA }}$ & $98 / 22$ & $97 / 22$ \\
\hline $\mathrm{X}_{\text {MMA or } \mathrm{S}}$ & $89 / 22$ & $64 / 22$ \\
\hline $\mathrm{M}_{\mathrm{n}, \mathrm{th}}$ & 4700 & 2730 \\
\hline$M_{n, \exp } / \bigoplus$ & $6250 / 1.116$ & $2360 / 1.11$ \\
\hline $\mathrm{L} \%$ & 94.3 & 80.7 \\
\hline
\end{tabular}



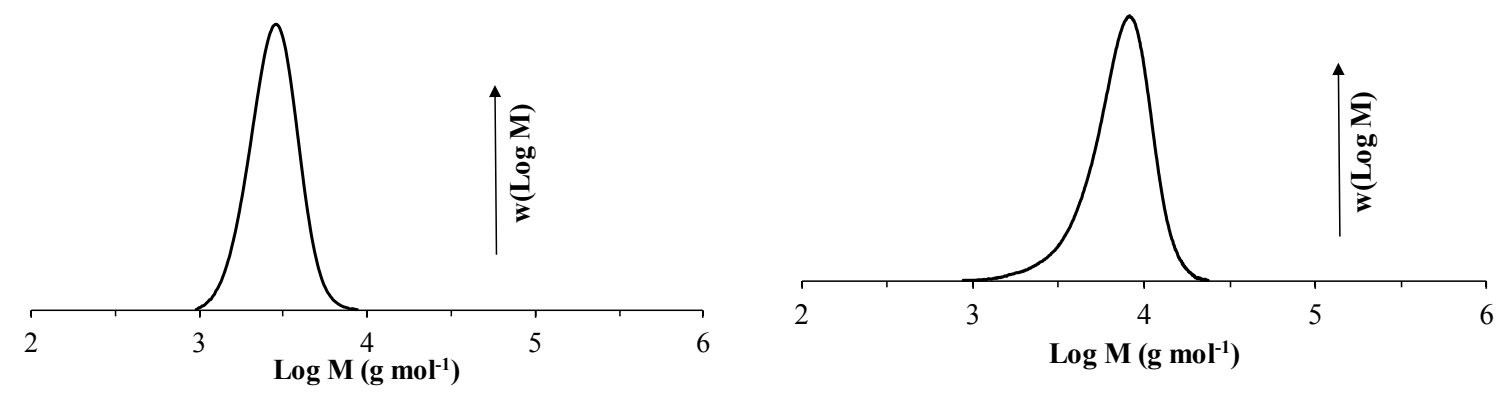

Figure SI2 - Molecular weight distributions of (A) $\mathrm{PMAA}_{62}-b-\mathrm{PMMA}_{11}-\mathrm{C} 12$ and (B)PAA ${ }_{24}-$ $b$-PS ${ }_{6}$-C12 synthesized by two-steps RAFT solution polymerization based on recipe in Table SI2. 
(A) $\mathrm{PAA}_{42}-\mathrm{Ac}$

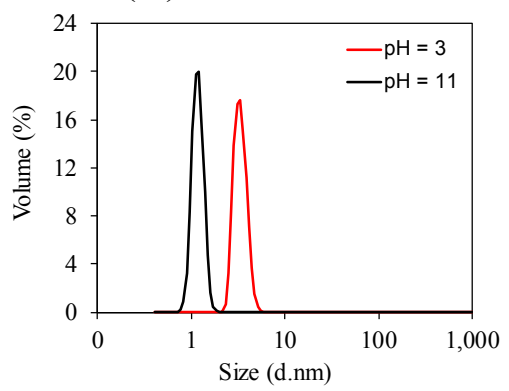

(D) $\mathrm{PMAA}_{43}-\mathrm{AC}$

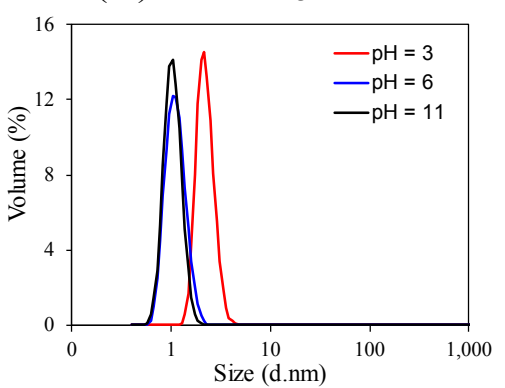

(G) PMAA $_{60}-\mathrm{C} 4$

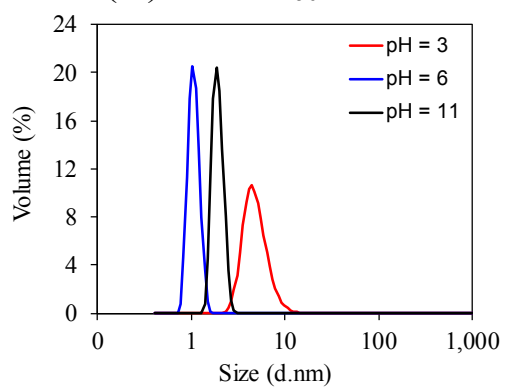

(J) PMAA $_{62}-b-\mathrm{PMMA}_{11}-\mathrm{C} 12$

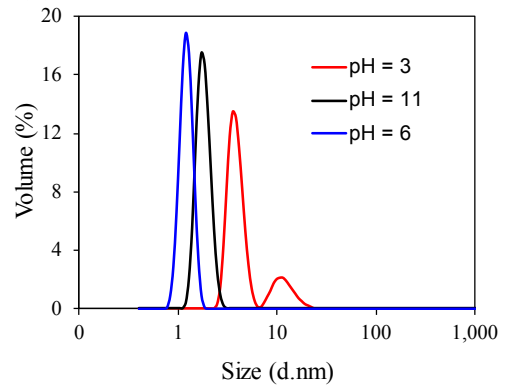

(B) $\mathrm{PAA}_{42}-\mathrm{C} 4$

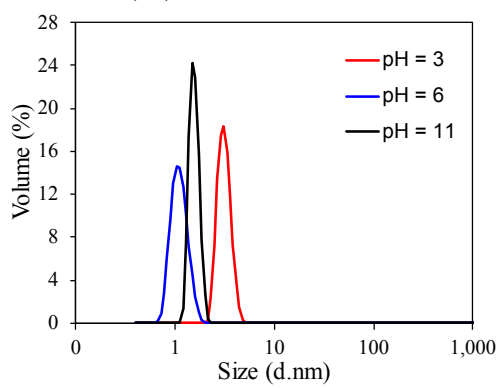

(E) $\mathrm{PMAA}_{20}-\mathrm{C} 4$

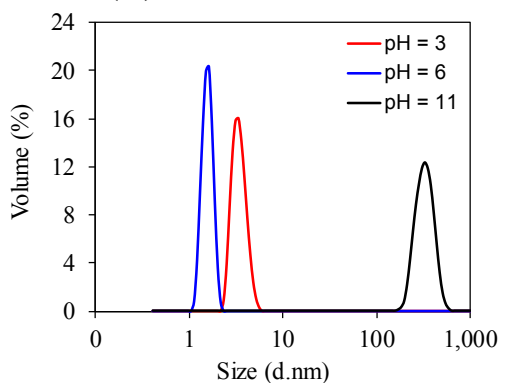

(H) $\mathrm{PMAA}_{119}-\mathrm{C} 4$

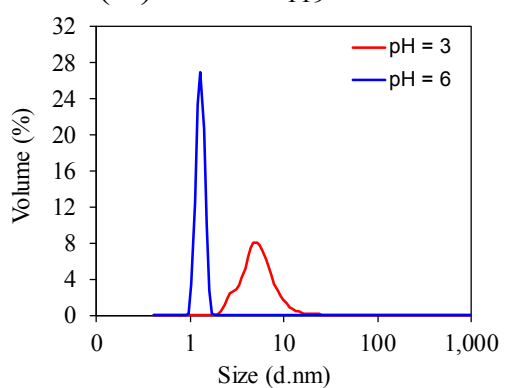

(C) $\mathrm{PAA}_{46}-\mathrm{C} 12$

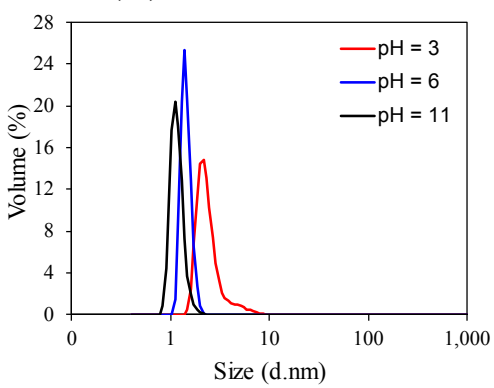

(F) $\mathrm{PMAA}_{41}-\mathrm{C} 4$

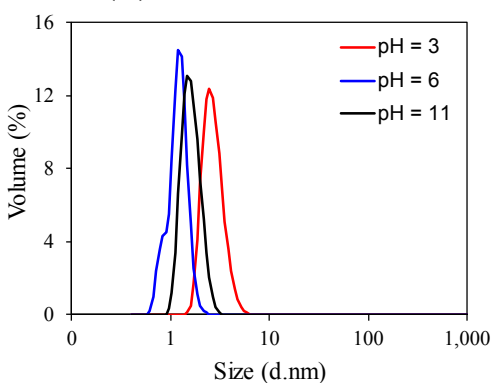

(I) $\mathrm{PMAA}_{42}-\mathrm{C} 12$

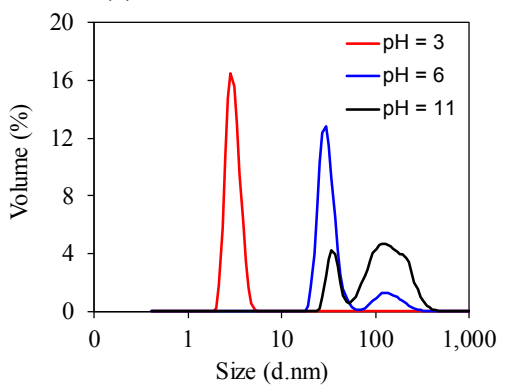

(K) $\mathrm{PAA}_{24}-b-\mathrm{PS}_{6}-\mathrm{C} 12$

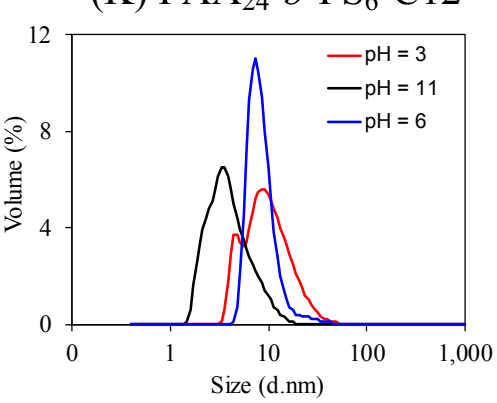

Figure SI3 - Size (d.nm) vs Volume (\%) Particle Size Distributions of macroRAFT agents at $\mathrm{pH}=3,6$ and 11 (no salt). 
Table SI3 - Particle Size by DLS of $9 \times 10^{-3} \mathrm{~mol} \mathrm{~L}^{-1}$ macroRAFT solutions containing 0.9 $\mathrm{mol} \mathrm{L} \mathrm{L}^{-1} \mathrm{KCl}$ at $\mathrm{pH}=3,6$ and 11

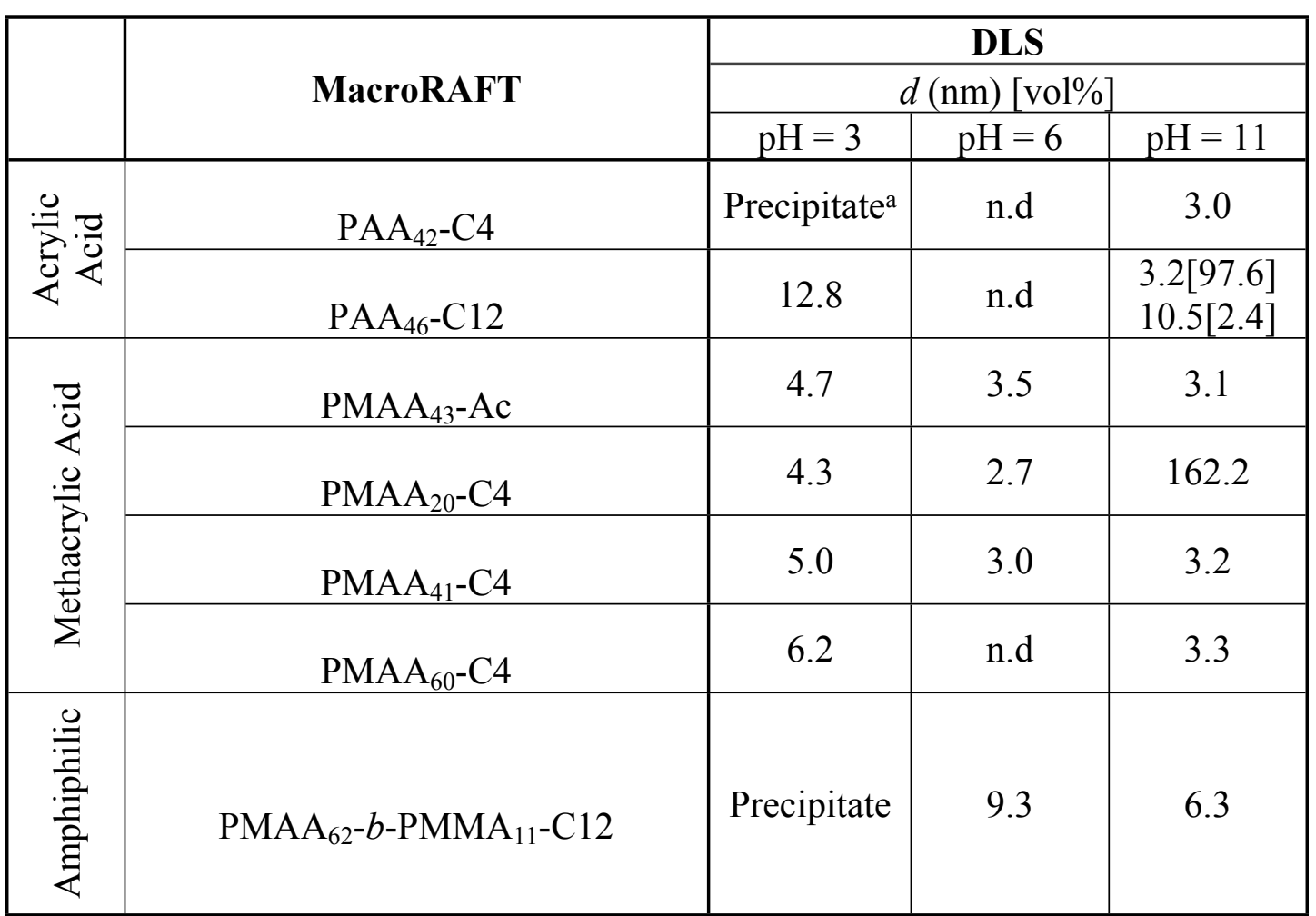

${ }^{a}$ No DLS measurement could be taken due to precipitate forming in solution 
(A) $\mathrm{PAA}_{42}-\mathrm{C} 4$

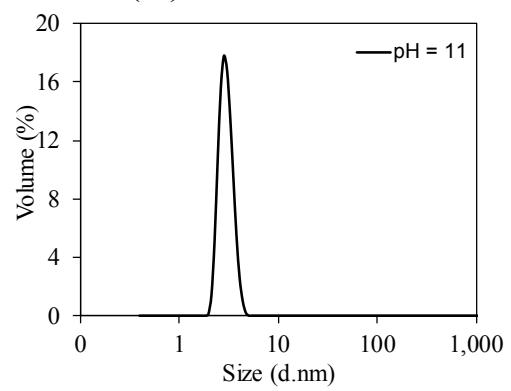

(D) $\mathrm{PMAA}_{20}-\mathrm{C} 4$

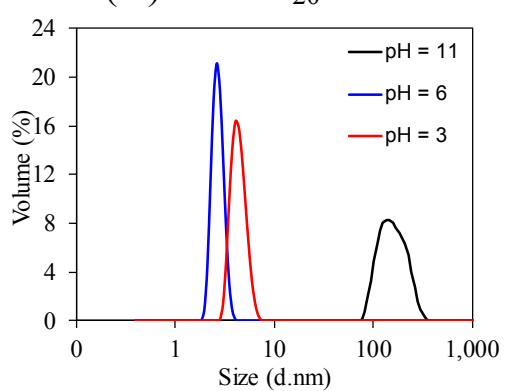

(B) $\mathrm{PAA}_{46}-\mathrm{C} 12$

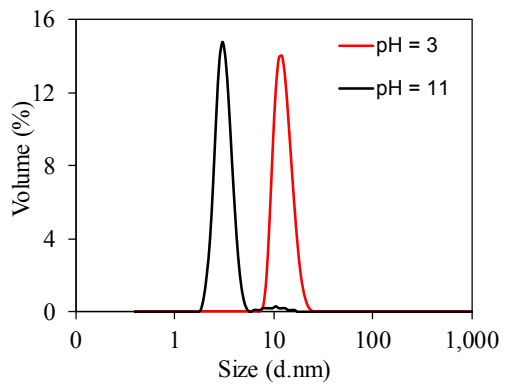

(E) $\mathrm{PMAA}_{41}-\mathrm{C} 4$

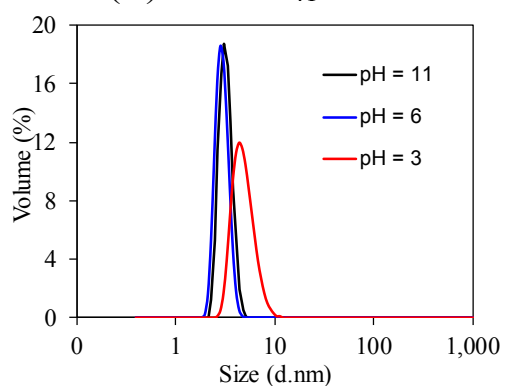

(G) PMAA $_{62}-b-\mathrm{PMMA}_{11}-\mathrm{C} 12$

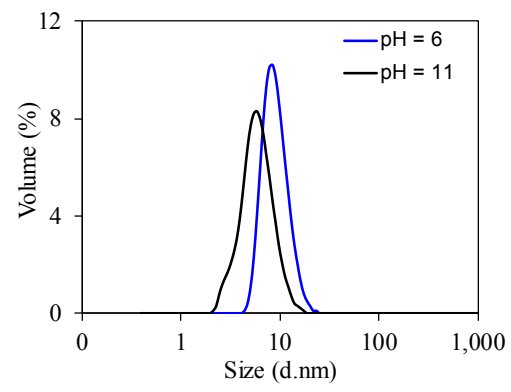

(C) $\mathrm{PMAA}_{43}-\mathrm{AC}$

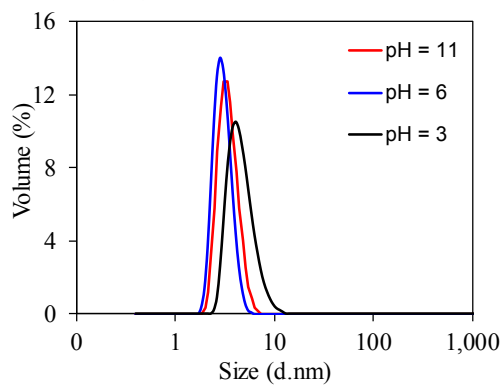

(F) PMAA $_{60}-\mathrm{C} 4$

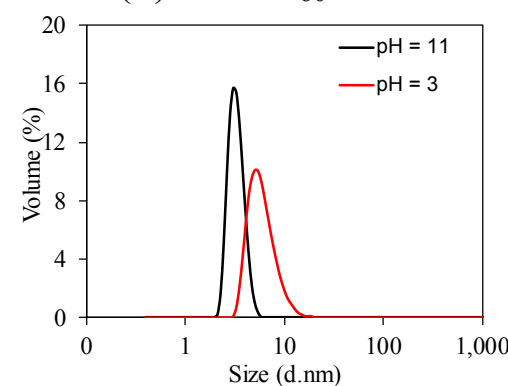

Figure SI4 - Size (d.nm) vs Volume (\%) Particle Size Distributions of macroRAFT agents at $\mathrm{pH}=3,6$ and 11 with $0.9 \mathrm{~mol} \mathrm{~L}^{-1} \mathrm{KCl}$

(A)

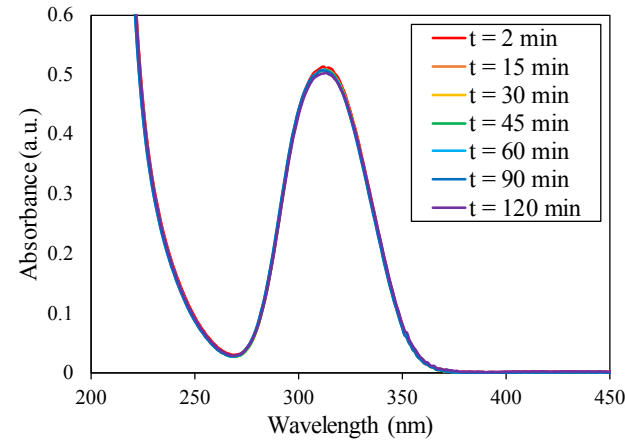

(B)

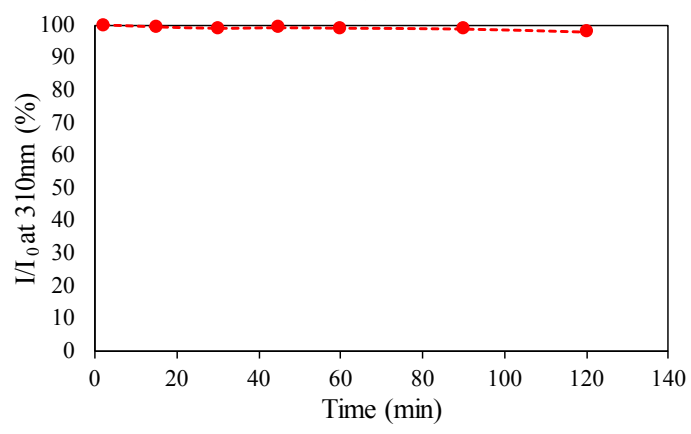

Figure SI5 - UV-vis absorption of $0.2 \mathrm{~g} \mathrm{~L}^{-1}$ solution of $\mathrm{PMAA}_{41}-\mathrm{C} 4$ at $\mathrm{pH}=11$ vs time. (A) $\mathrm{UV}$-vis spectra and (B) Ratio of absorbance intensity $\left(\mathrm{I} / \mathrm{I}_{0}\right)$ at maximum absorbance wavelength $(310 \mathrm{~nm})$ as a function time. 


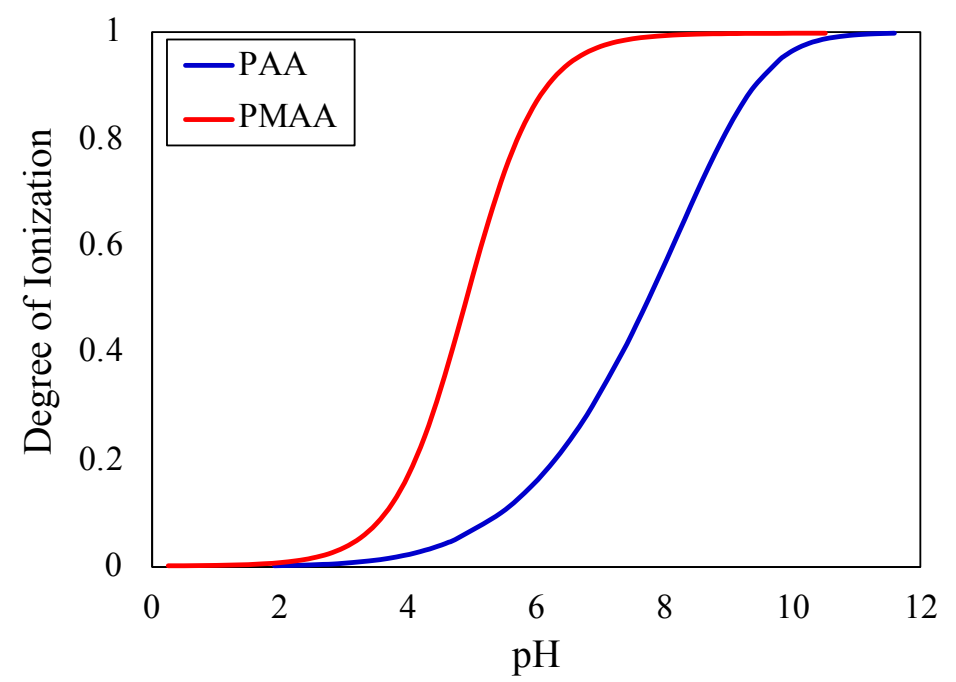

Figure SI6 - Degree of ionization vs. $\mathrm{pH}$ for $\mathrm{PAA}^{1}$ and $\mathrm{PMAA}^{2}$ calculated based on previous work: PAA $\left(\mathrm{p} K_{\mathrm{a}}=4.5 \text { and } \mathrm{n}=4.1\right)^{1}$ and PMAA (syndiotactic, $\mathrm{p} K_{\mathrm{a}}=4.9$ and $\left.\mathrm{n}=0.76\right) .{ }^{2}$ Note that the $\mathrm{p} K_{\mathrm{a}}$ does not match the $\mathrm{pH}$ at which $50 \%$ of the functional groups are protonated. This is caused by the complex relationship between the degree of ionization and $\mathrm{pH}$ for weak polyelectrolytes as well-established in the literature. , $^{3,4}$

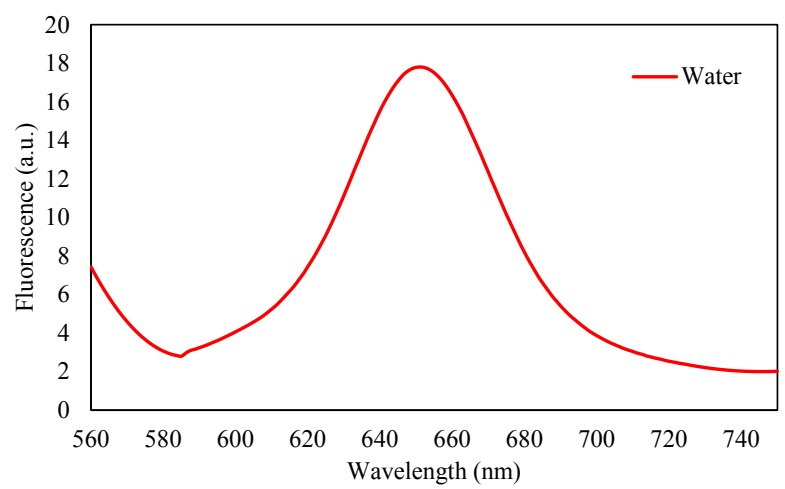

Figure SI7- Fluorescence spectra of $1.2 \times 10^{-6} \mathrm{~mol} \mathrm{~L}^{-1}$ Nile Red in $3 \mathrm{ml}$ distilled water, excitation wavelength at $550 \mathrm{~nm}$ and excitation bandwidth and emission bandwidth both set at $5.0 \mathrm{~nm}$

(A)

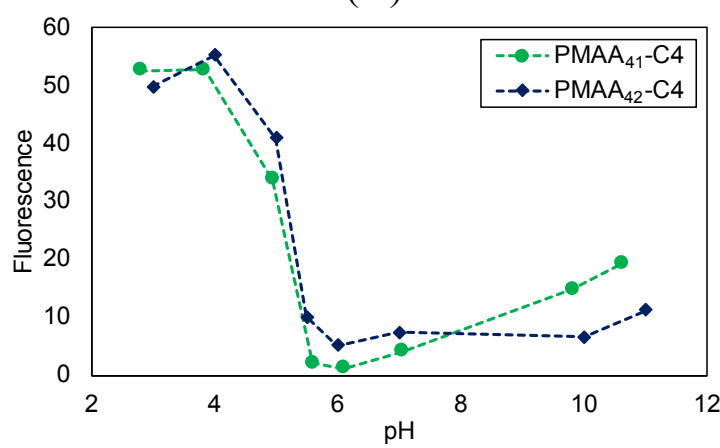

(B)

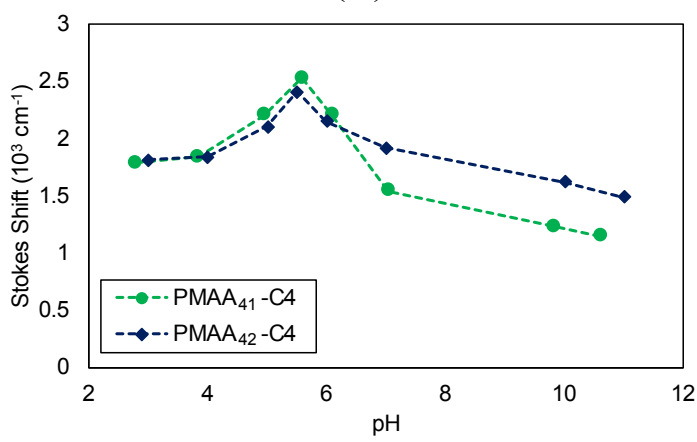

Figure SI8 - Spectrofluorescence of $\mathrm{PMAA}_{41}-\mathrm{C} 4$ and $\mathrm{PMAA}_{42}-\mathrm{C} 4$ in aqueous solution at different $\mathrm{pH}$ using Nile Red as solvachromatic dye. (A) Fluorescence intensity at $\lambda_{\max }$ with excitation wavelength at 550nm and (B) Stokes shift. 


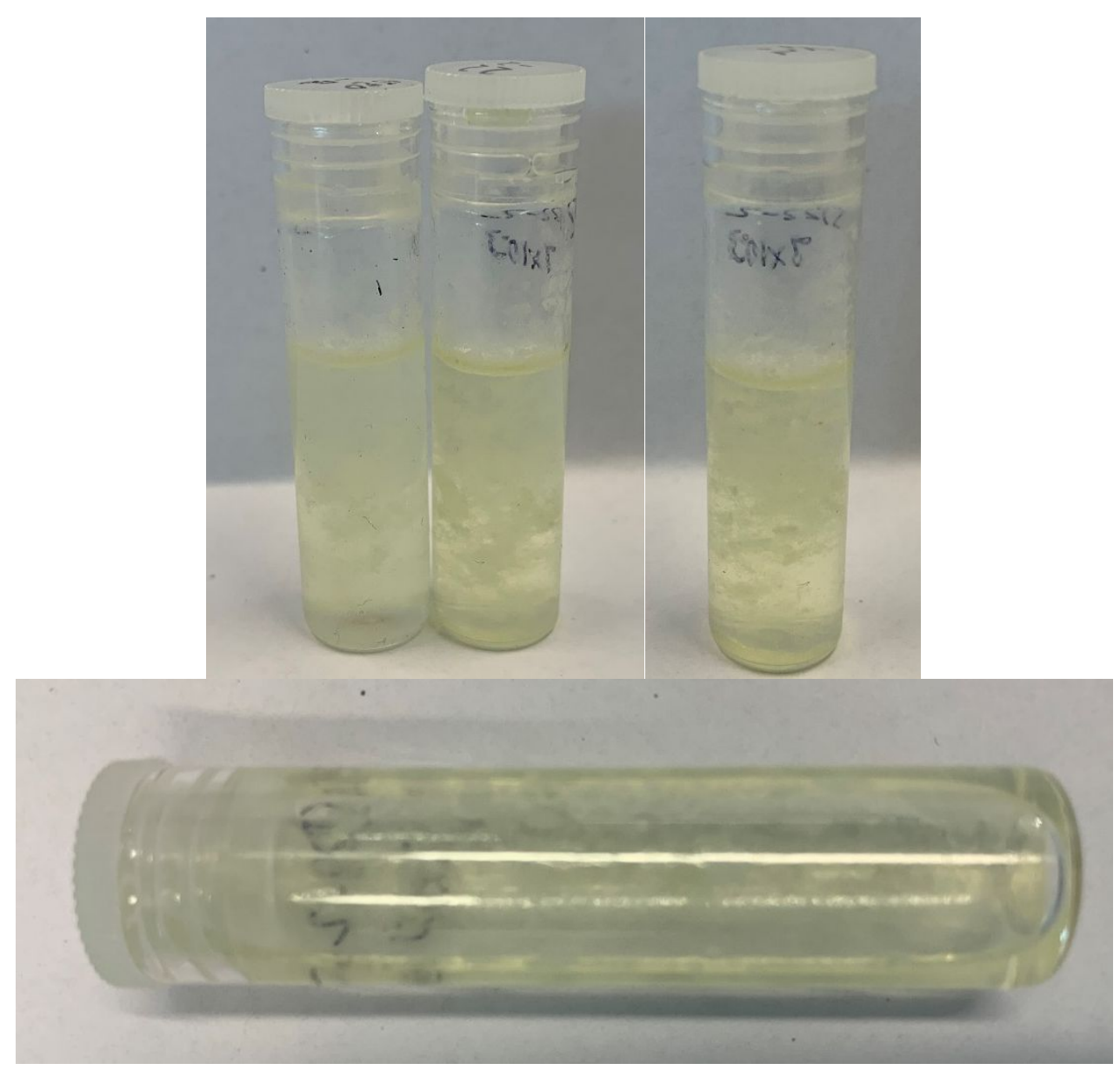

Figure SI9 - $\mathrm{PMAA}_{42}-\mathrm{C} 12$ solutions at $\mathrm{pH}=11$, after being left at room temperature for 1 week. 
(A)
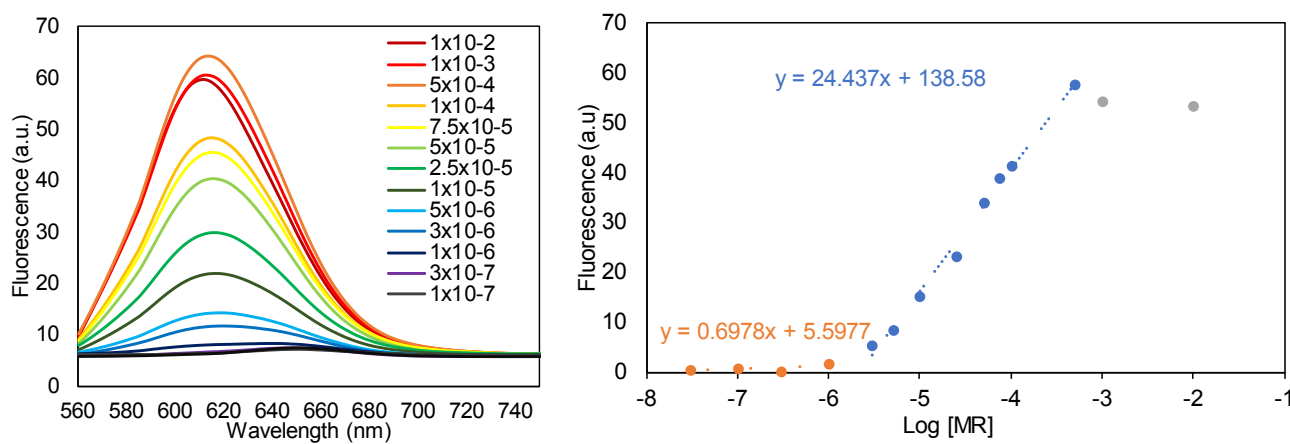

(B)
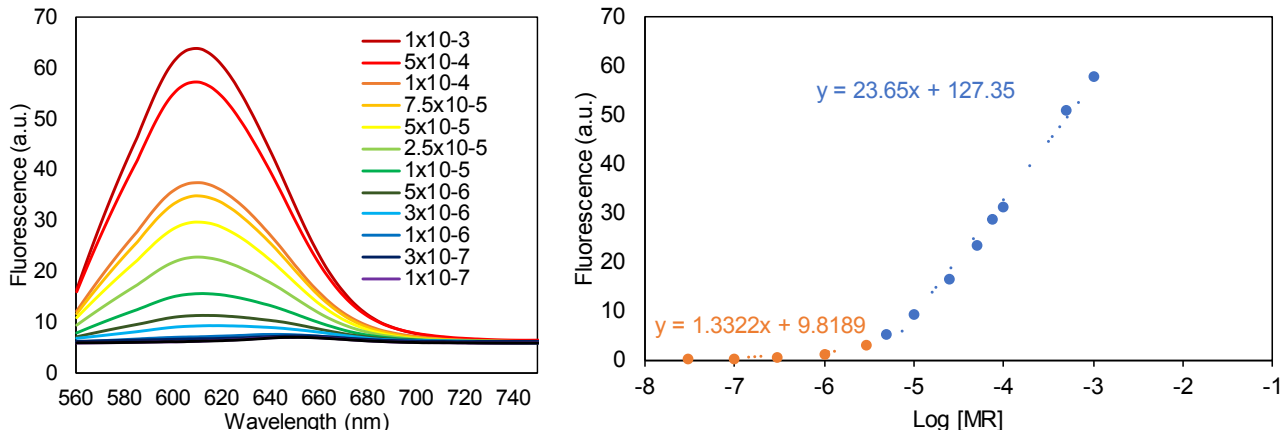

(C)
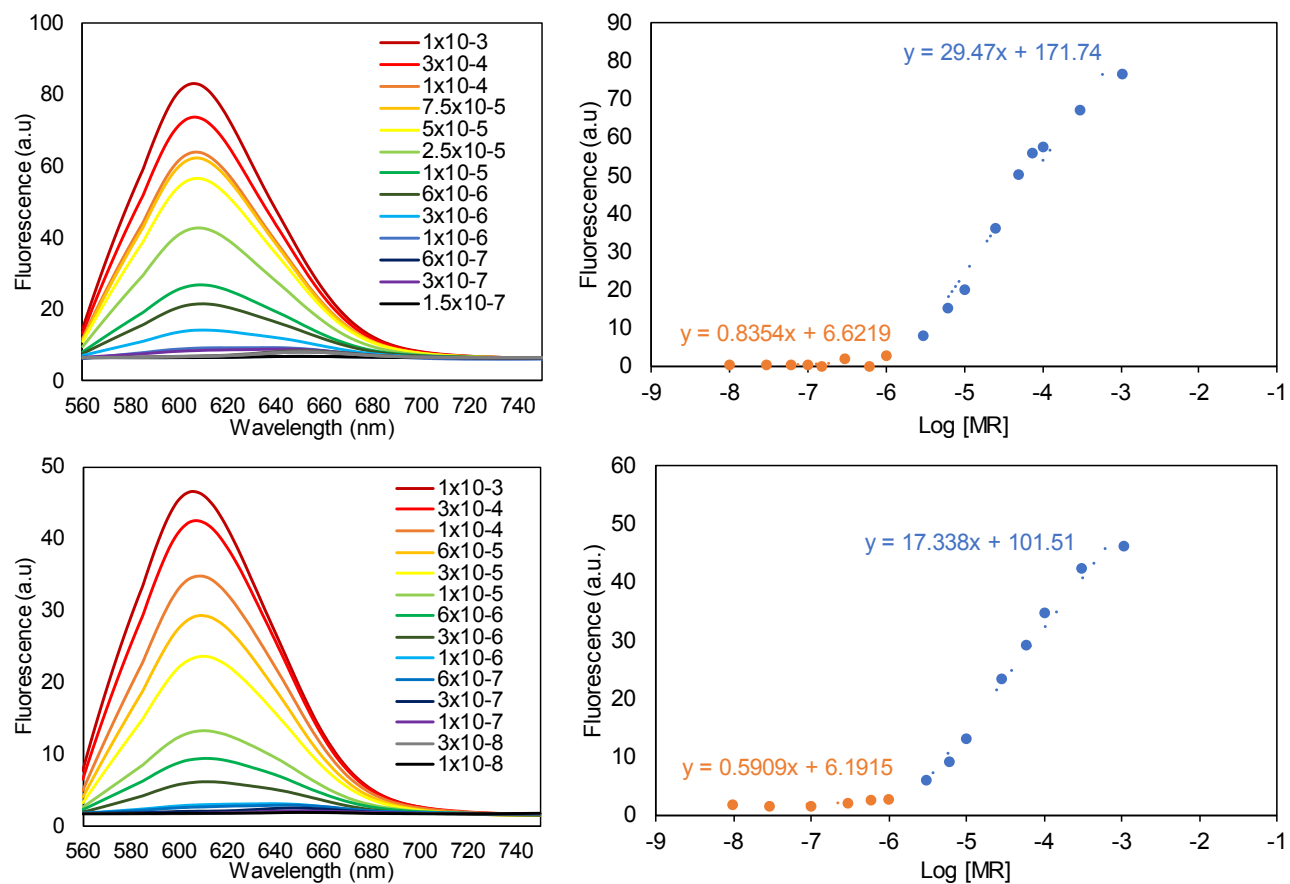

Figure SI10 - Fluorescence and linearisations of PMAA based macroRAFTs with different Zgroup in aqueous solution at $\mathbf{p H}=\mathbf{3}$ with different concentrations ranging between $1 \times 10^{-7}$ $1 \times 10^{-2} \mathrm{~mol} / \mathrm{L}$ with Nile Red as solvachromatic dye. (A) PMAA $43-\mathrm{Ac}$ (B) PMAA ${ }_{41}-\mathrm{C} 4$ (C) $\mathrm{PMAA}_{42}-\mathrm{C} 12$ (D) $\mathrm{PMAA}_{62}-b-\mathrm{PMMA}_{11}-\mathrm{C} 12$ Left: Spectra of aqueous solutions of PMAAbased macroRAFT as a function of concentration Right: Fluorescence at $\lambda_{\max }$ plotted against $\log [\mathrm{MR}]$. 
(A)
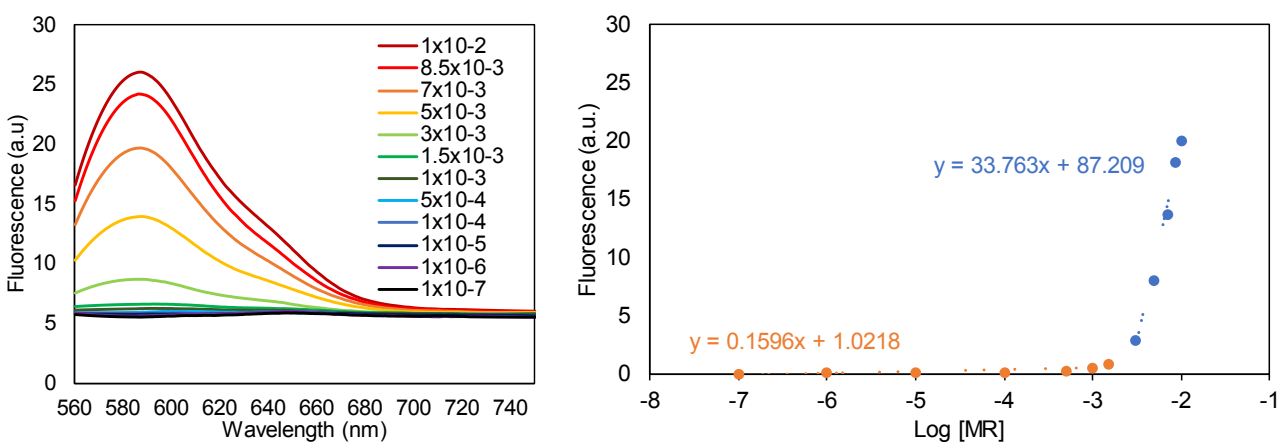

(B)
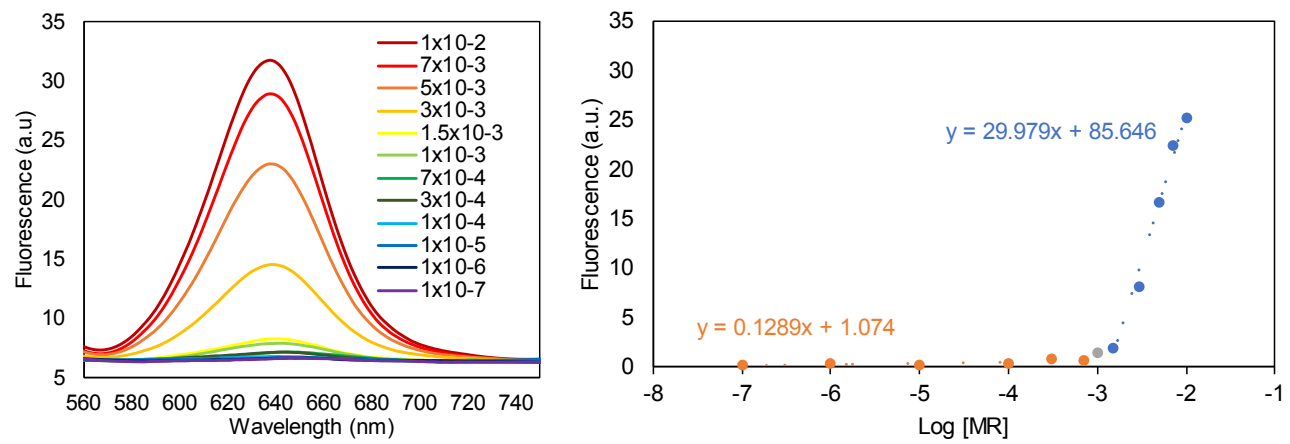

(C)
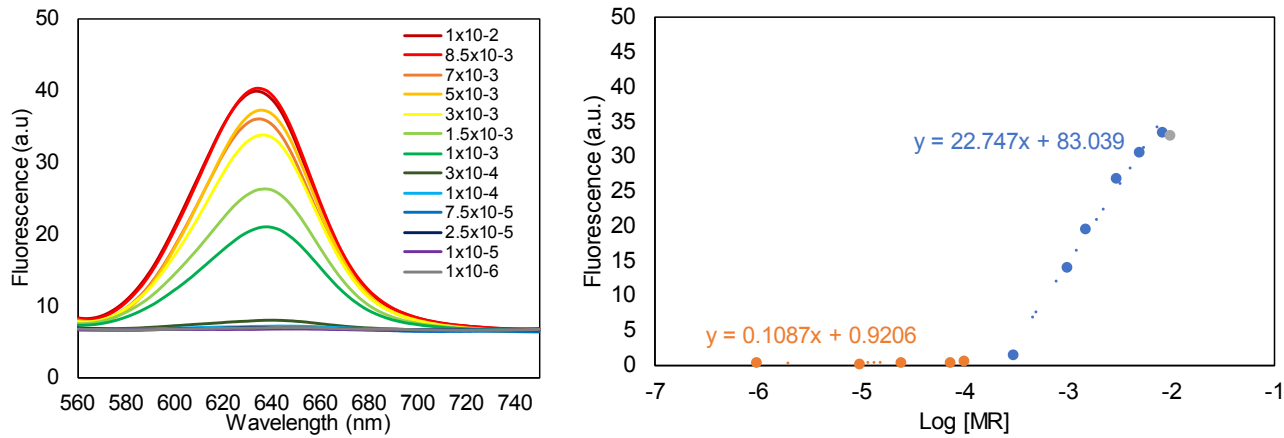

Figure SI11 - Fluorescence and linearisations of PMAA-based macroRAFTs with different Zgroup in aqueous solution at $\mathbf{p H}=\mathbf{1 1}$ with different concentrations ranging between $1 \times 10^{-7}$ $1 \times 10^{-2} \mathrm{~mol} / \mathrm{L}$ with Nile Red as solvachromatic dye. (A) PMAA $41-\mathrm{C} 4$ (B) PMAA $42-\mathrm{C} 12$ (C) PMAA $_{62}-b$-PMMA $11-\mathrm{C} 12$ Left: Spectra of aqueous solutions of PMAA-based macroRAFT as a function of concentration Right: Fluorescence at $\lambda_{\max }$ plotted against $\log [\mathrm{MR}]$. 
(A)
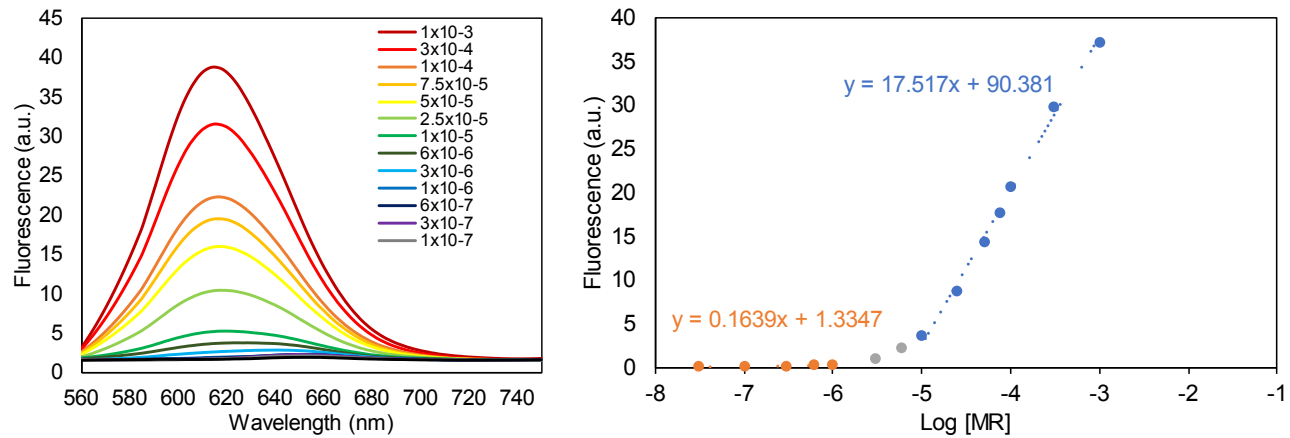

(B)
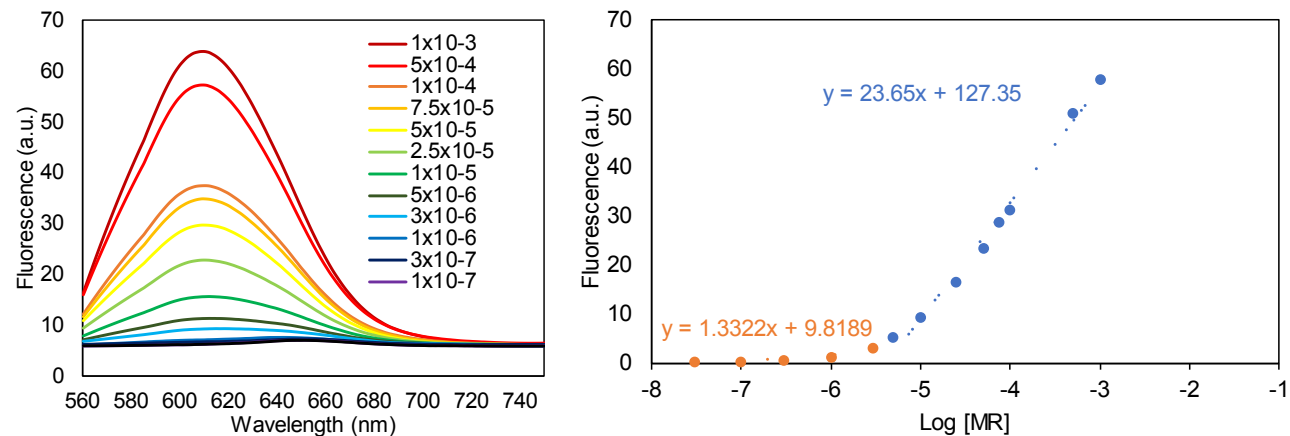

(C)
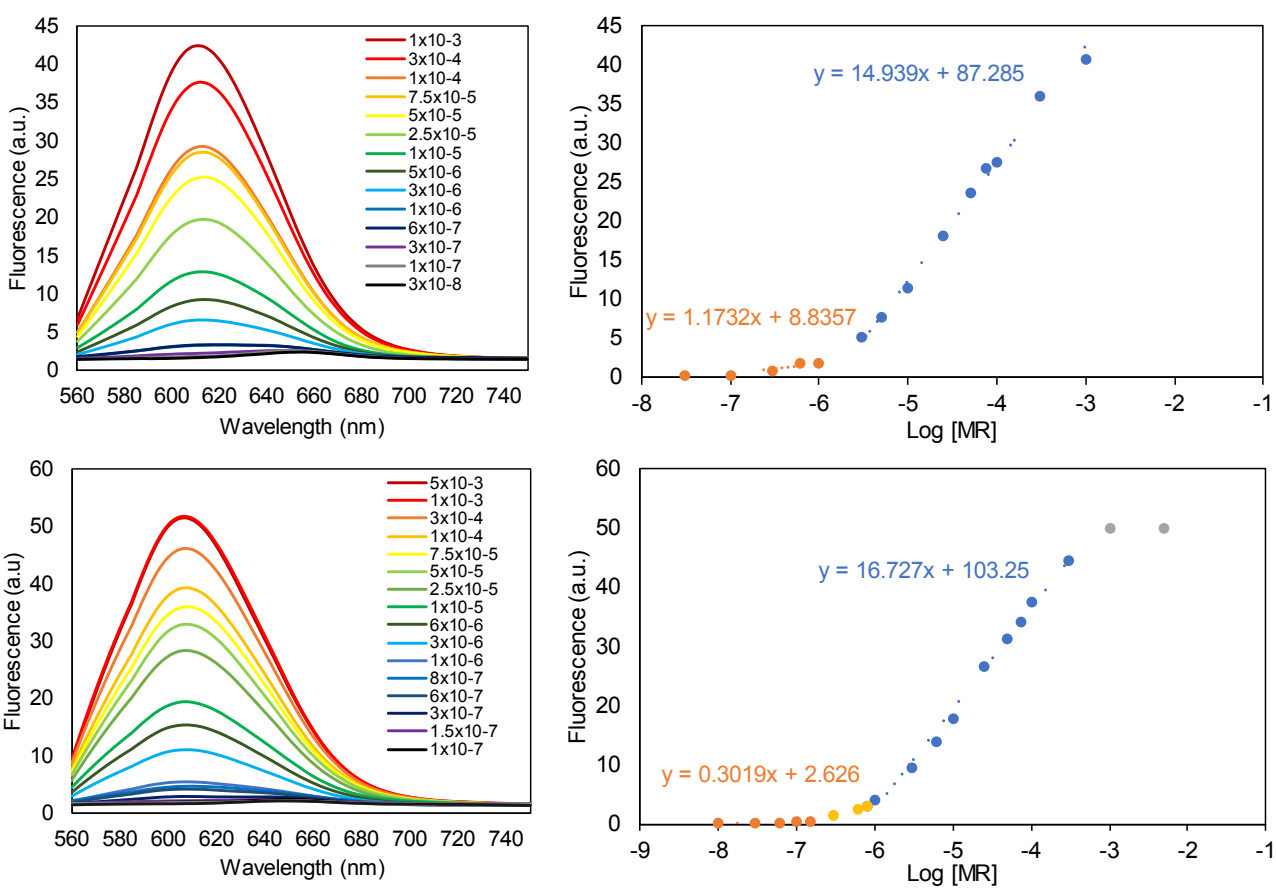

Figure SI12 - Effect of MW on Fluorescence and linearisations of PMAA-C4-based macroRAFTs in aqueous solution at $\mathbf{p H}=\mathbf{3}$ with different concentrations ranging between $3 \times 10^{-8}-1 \times 10^{-3} \mathrm{~mol} / \mathrm{L}$ with Nile Red as solvachromatic dye. (A) $\mathrm{PMAA}_{20}$-C4 (B) PMAA ${ }_{41}-\mathrm{C} 4$ (C) PMAA $0_{60}$-C4 (D) PMAA $11^{-}$-C4 Left: Spectra of aqueous solutions of PMAA-C4-based macroRAFT as a function of concentration Right: Fluorescence at $\lambda_{\max }$ plotted against $\log$ $[\mathrm{MR}]$. 
(A)
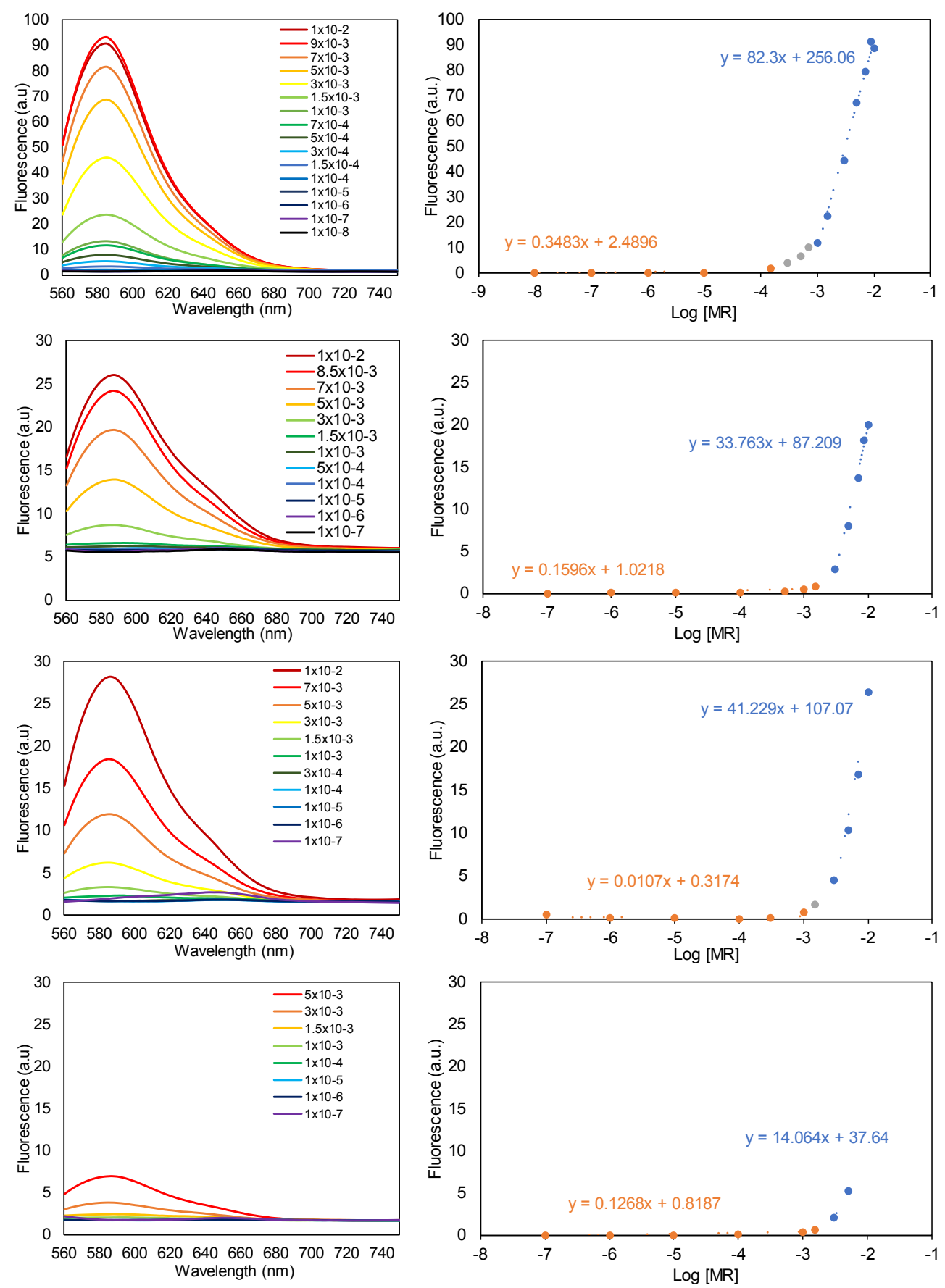

Figure SI13 - Effect of MW on Fluorescence and linearisations of PMAA-C4-based MacroRAFTs in aqueous solution at $\mathbf{p H}=\mathbf{1 1}$ with different concentrations ranging between $1 \times 10^{-8}-1 \times 10^{-2} \mathrm{~mol} / \mathrm{L}$ with Nile Red as solvachromatic dye. (A) $\mathrm{PMAA}_{20}$-C4 (B) PMAA $41^{-\mathrm{C}} 4$ (C) PMAA $_{60}-\mathrm{C} 4$ (D) PMAA $119^{-}$C4 Left: Spectra of aqueous solutions of PMAA-C4-based macroRAFT as a function of concentration Right: Fluorescence at $\lambda_{\max }$ plotted against $\log$ [MR]. 


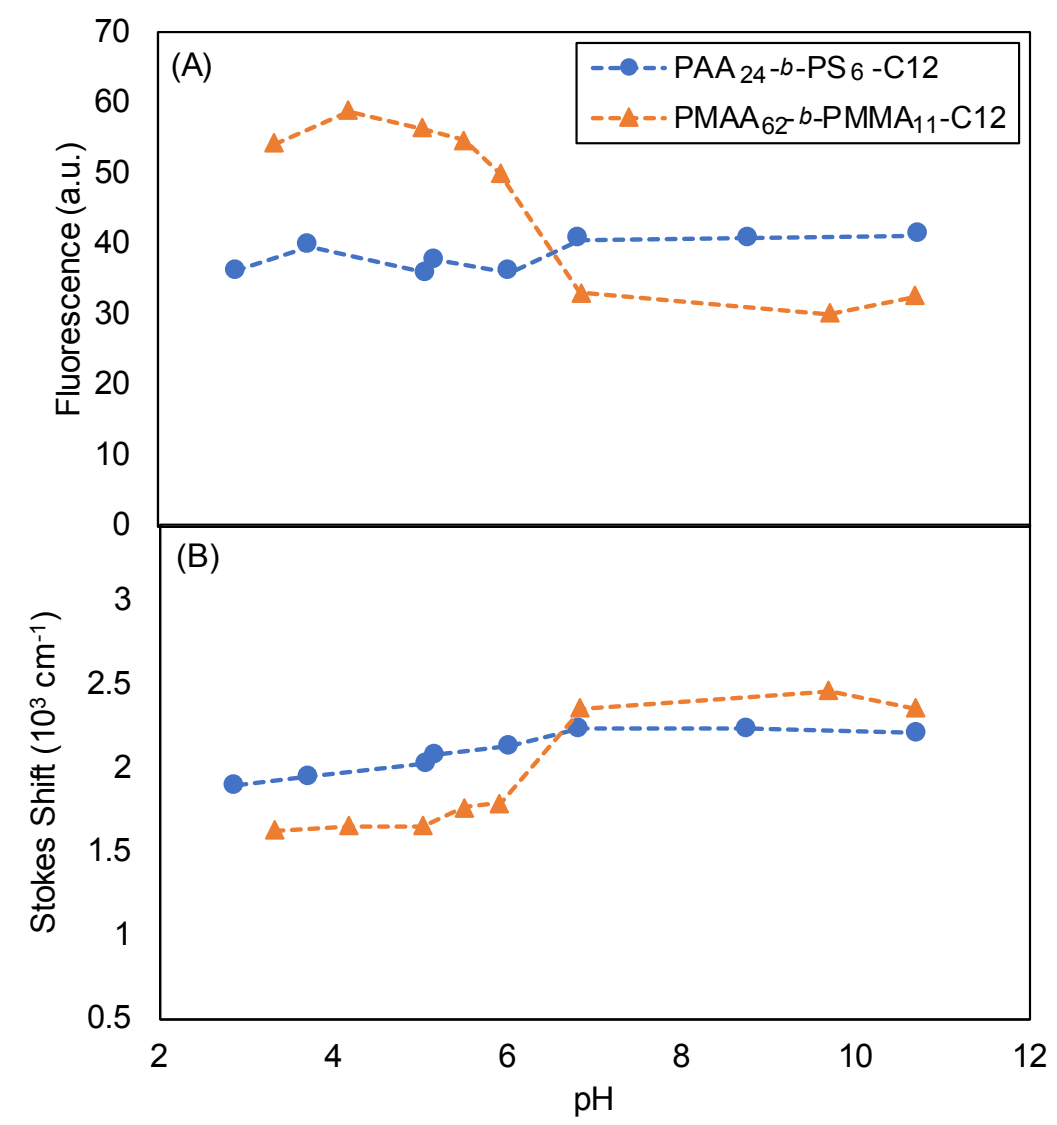

Figure SI14 - Spectrofluorescence of amphiphilic PMAA- $b$-PMMA-C12 and PAA- $b$-PS-C12 in aqueous solution at different $\mathrm{pH}$ using Nile Red as solvachromatic dye. (A) Fluorescence intensity at $\lambda=$ maximum with excitation wavelength at $550 \mathrm{~nm}$, (B) Stokes shift. 
(A)
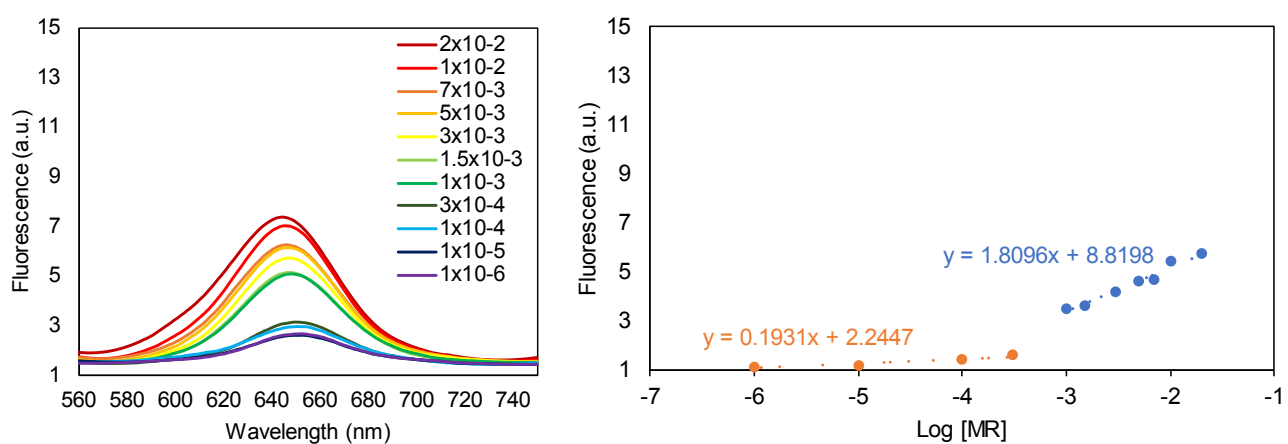

(B)
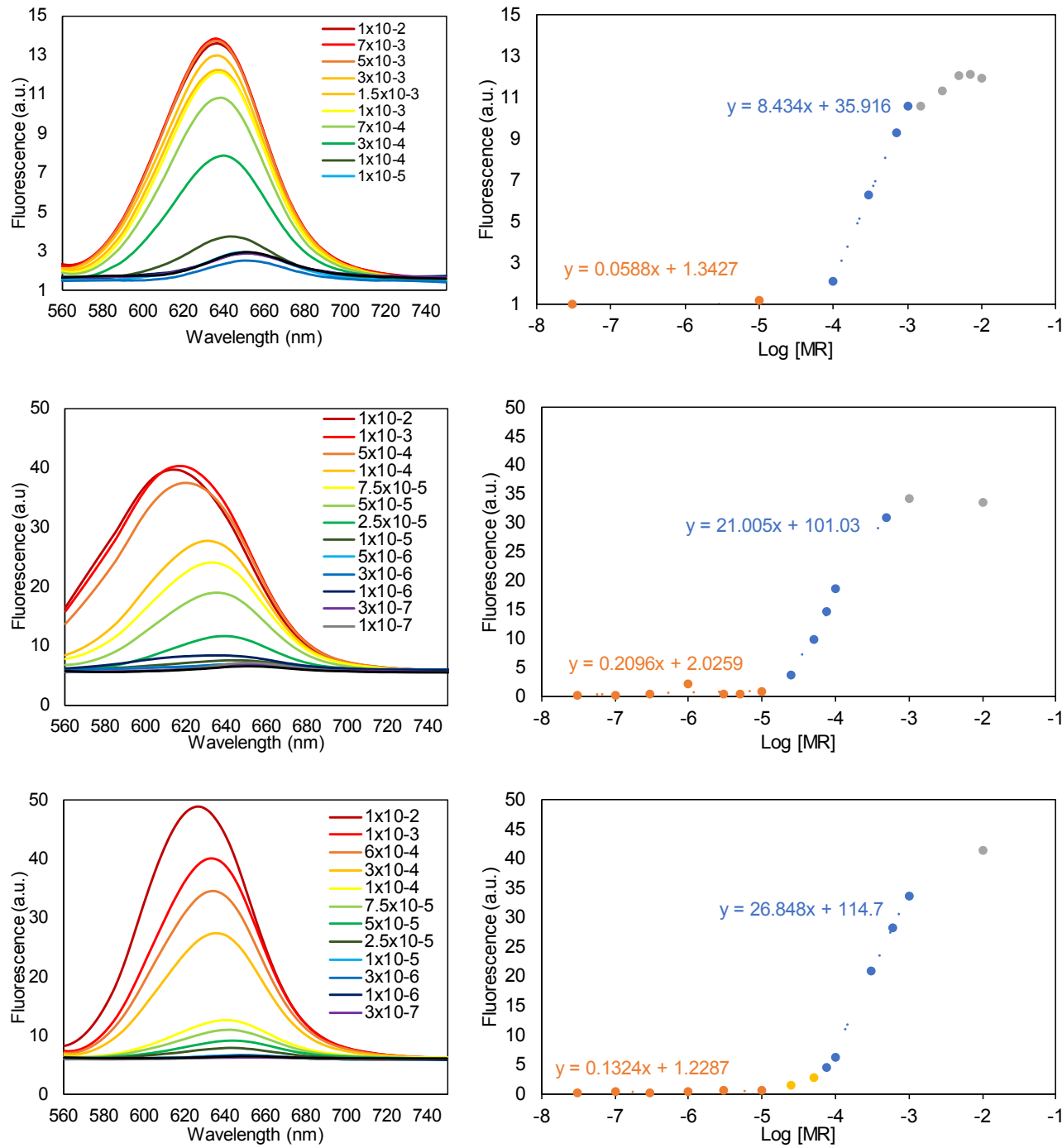

Figure SI15- Fluorescence and linearisations of hydrophilic PAA-based MacroRAFTs with different $Z$-groups in aqueous solution at $\mathbf{p H}=\mathbf{3}$ and $\mathrm{PAA}_{24}-b-\mathrm{PS}_{6}$ at $\mathrm{pH}=3$ and 11 with different concentrations ranging between $1 \times 10^{-7}-2 \times 10^{-2} \mathrm{~mol} / \mathrm{L}$ with Nile Red as solvachromatic dye. (A) $\mathrm{PAA}_{42}-\mathrm{C} 4$ (B) $\mathrm{PAA}_{46}-\mathrm{C} 12$ (C) $\mathrm{PAA}_{24}-b-\mathrm{PS}_{6}-\mathrm{C} 12$ at $\mathrm{pH}=3$ (D) $\mathrm{PAA}_{24}-b-\mathrm{PS}_{6}-\mathrm{C} 12$ at $\mathrm{pH}=11$ Left: Spectra of aqueous solutions of PAA-based macroRAFT as a function of concentration Right: Fluorescence at $\lambda_{\max }$ plotted against $\log$ [MR]. 


\section{REFERENCES}

1. Swift, T.; Swanson, L.; Geoghegan, M.; Rimmer, S., The pH-responsive behaviour of poly(acrylic acid) in aqueous solution is dependent on molar mass. Soft Matter 2016, 12 (9), 2542 2549.

2. $\quad$ Sharma, A.; Smith, J. D.; Walters, K. B.; Rick, S. W., Constant pH simulations of pH responsive polymers. J. Chem. Phys. 2016, 145 (23), 234906.

3. Katchalsky, A.; Spitnik, P., Potentiometric titrations of polymethacrylic acid. J. Polym. Sci. 1947, 2 (4), 432-446.

4. $\quad$ Mandel, M., The potentiometric titration of weak polyacids. Eur. Polym. J. 1970, 6 (6), 807822. 